\title{
$\mathfrak{B e r f}$ Der interen Mifífinn
}

in Dex

ebangelifanen Sitrhe ber Ribeinprobinz.

Bon

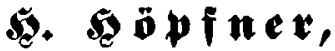

Sonfiftorialrath zu c5oblenz.

Dienet einander, ein 3eglider mit ber Babe, die ex empfangen hat, als bie guten Saubhalter ber manterlei Bnade (3)ottes.

1 petr. 4, 10.

\section{$\mathfrak{B} \mathbf{n} \mathbf{n}$,}

$\mathfrak{b e i} \mathfrak{A b o l p h} \mathfrak{M a r} \mathfrak{a} \mathfrak{s}$.

1876. 
